\title{
Effect of Electrostatic Discharge on Digital and Analog Circuits
}

\author{
${ }^{1}$ Rajashree Narendra, ${ }^{2}$ M.L.Sudheer, ${ }^{3}$ D.C. Pande \\ ${ }^{I}$ (Department of of Telecommunication / BNMIT, Bangalore) \\ ${ }^{2}$ (Department of ECE / UVCE, Bangalore) \& ${ }^{3(E M I / E M C ~ G r o u p, ~ L R D E, ~ B a n g a l o r e) ~}$
}

\begin{abstract}
A comparative study of the effects of electrostatic discharge (ESD) on digital and analog circuits is carried out. Direct and Indirect discharge is performed on the circuit having both analog and digital circuitry. First the Indirect discharge on the ground plane is done for different voltages and distances. Then the direct air discharge is performed near the digital and discreet analog circuitry. These results are compared and the effect of electrostatic discharge over digital and analog circuits is summarized from the experimental results.
\end{abstract}

Keywords:- Electrostatic Discharge; Indirect discharge; Direct air discharge; Analog circuit; Digital circuit; ESD simulator; Electromagnetic Interference

\section{INTRODUCTION}

Digital circuits are more susceptible to electrostatic discharge (ESD) than analog circuits. Most of the electronic components that are considered fairly rugged can be damaged by ESD. Bipolar transistors, the earliest of the solid state amplifiers, are not immune to ESD, though less susceptible. There are components that might not be considered at risk, such as some specialized resistors and capacitors. Devices manufactured using MOS (Metal Oxide Semiconductor) technology is more susceptible to ESD [1-4] but some of the newer high speed components can be ruined with low voltages.

Damage to components can, and usually do, occur when the part is in the ESD path. Many components in the circuits are very robust, can handle the discharge and undergo upsets. But if a part has a small or thin geometry as part of their physical structure then the voltage can break down that part of the semiconductor [58]. Currents during the ESD events become quite high, but are in the nanosecond to microsecond time frame. Part of the component is left permanently damaged by this, which can cause two types of failure modes. Catastrophic is the easy one, leaving the part completely nonfunctional. The other can be much more serious. Latent damage may allow the problem component to work for hours, days or even months after the initial damage before catastrophic failure. Many times these parts are referred to as "walking wounded", since they are working but bad. If these components end up in a life support role, such as medical or military use, then the consequences can be grim.

Indirect discharge on the horizontal coupling plane (HCP) and direct air discharge is performed $[9,10]$. The ESD indirect discharge test was carried out to verify the ESD immunities of the analog and digital components in the circuit.

\section{CIRCUIT DIAGRAM AND ITS OPERATION}

The RC Phase Shift Oscillator produces a sine wave output signal using regenerative feedback from the resistor-capacitor combination. This resistor-capacitor feedback network is connected as shown in the Fig. 1 as a phase advance network to produce a sine wave oscillation at a frequency of $912 \mathrm{~Hz}$ with a overall phaseshift of 360 degrees. By varying one or more of the resistors or capacitors in the phase-shift network, the frequency can be varied and generally this is done using a 3-ganged variable capacitor. As the resistorcapacitor combination in the RC Oscillator circuit also acts as an attenuator producing an attenuation of $1 / 29$ th $(\mathrm{Vo} / \mathrm{Vi}=\beta)$ per stage, the gain of the amplifier is adjusted sufficiently large to overcome the losses in the three mesh network.

Zero-crossing detector using inverting op-amp (IC $\mu \mathrm{A} 741$ ) comparator is depicted in Fig. 1. The circuit produces a change in the output state whenever the input crosses the reference. In this case the reference input is ground, hence every time the sine wave output crosses the $0 \mathrm{~V}$ level there will be a shift in the output voltage level.

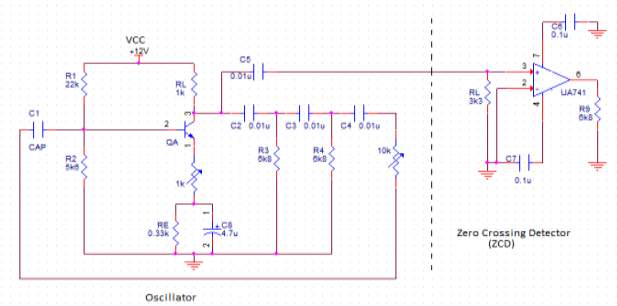

Fig. 1 Circuit diagram of RC phase-shift oscillator followed by zero crossing detector. 
The initial output of the circuit is shown in Fig. 2. The sine wave is the output of the oscillator, the two square waves are the output of the zero crossing detector.

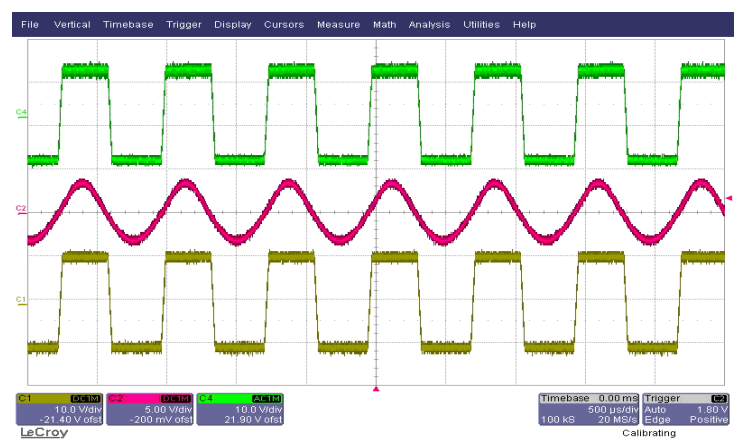

Fig. 2 Initial output of the circuit.

III. INDIRECT ESD DISCHARGE

Indirect discharge was done on the horizontal plane for different voltages and different distances. Some of them are presented and discussed. When a discharge of $4 \mathrm{kV}$ was given on the horizontal plane at a distance of $0.9 \mathrm{~m}$ there was a change in the ZCD output for $6.67 \mu$ s indicating shift of the oscillator output below $0 \mathrm{~V}$ for that period of time as shown in Fig. 3.

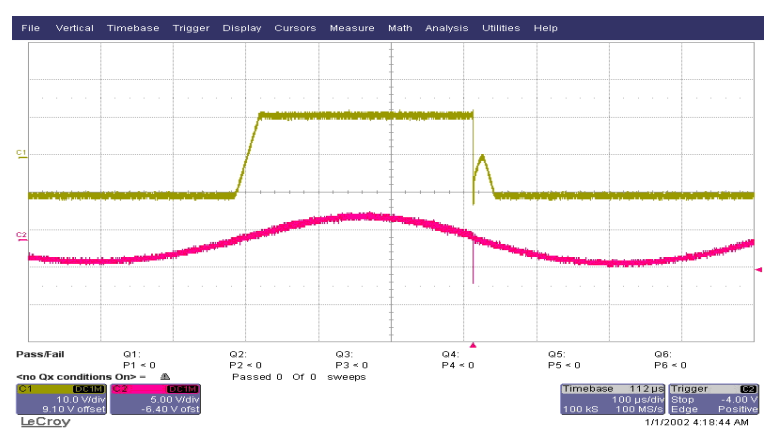

Fig. 3 Effect of ESD at $4 \mathrm{kV}$ and at a distance of $0.9 \mathrm{~m}$

The oscillator output goes below the reference voltage of $0 \mathrm{~V}$ twice when discharged at $8 \mathrm{kV}$ at a distance of about $0.9 \mathrm{~m}$ as shown in the Fig. 4. At the first instance it is for a period of about $2 \mu$ s and second instance for a period of $1 \mu \mathrm{s}$ which is indicated by the shift of the ZCD output.

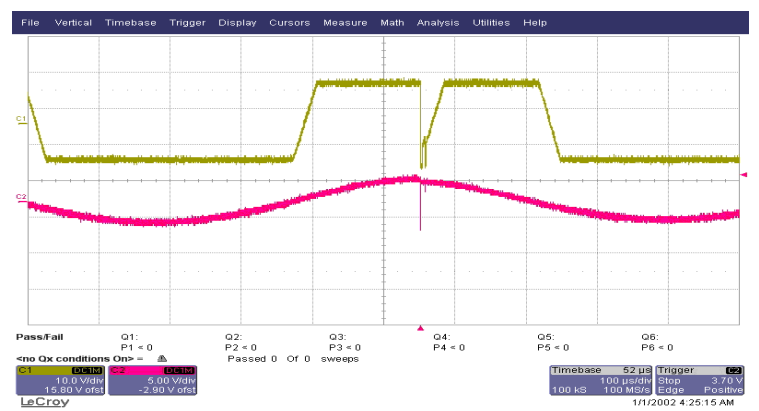

Fig. 4 Effect of ESD at $8 \mathrm{kV}$ and at a distance of $0.9 \mathrm{~m}$

A small phase shift and a transient of about $13 \mathrm{~V}$ is observed at the trigger point in the oscillator output when discharged at $15 \mathrm{kV}$ at a distance of $0.9 \mathrm{~m}$ as shown in Fig. 5 . But a very small transient of about $1 \mathrm{~V}$ is observed in the ZCD output because of the data being low at the point of trigger. 


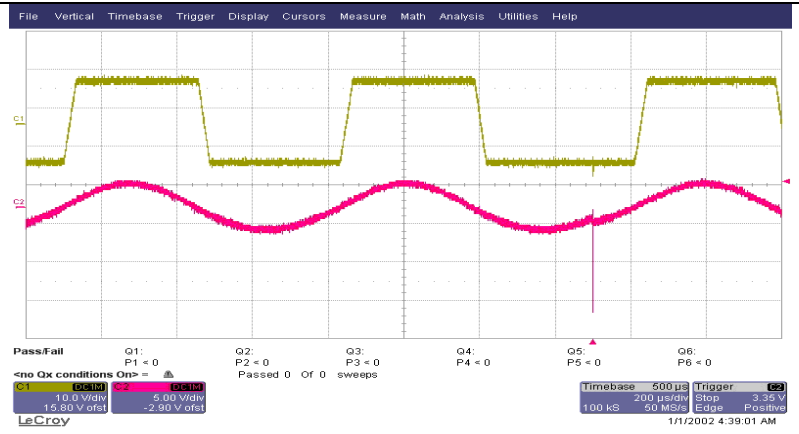

Fig. 5 Effect of ESD at $15 \mathrm{kV}$ and at a distance of $0.9 \mathrm{~m}$

The results tabulated are for different voltages at a constant distance of $0.9 \mathrm{~m}$ from the circuit.

\begin{tabular}{|l|l|l|}
\hline $4 \mathrm{kV}$ discharge at & $8 \mathrm{kV}$ discharge at & $15 \mathrm{kV}$ discharge at $0.9 \mathrm{~m}$ \\
$0.9 \mathrm{~m}$ & $0.9 \mathrm{~m}$ & \\
\hline Change in ZCD & Oscillator output & $1 \mathrm{~V}$ transient for ZCD \\
output and shift in & went below 0V twice & output and 13V \\
oscillator output for & and shift in ZCD & transient in oscillator \\
$6.67 \mu \mathrm{s}$ & output for $2 \mu \mathrm{s}$ & output \\
\hline
\end{tabular}

Now the results for a constant voltage of $8 \mathrm{kV}$ at different distances are discussed. The effect of ESD for $8 \mathrm{kV}$ at a distance of $0.9 \mathrm{~m}$ is already mentioned in Fig. 4 . When $8 \mathrm{kV}$ is discharged at a distance $0.7 \mathrm{~m}$, a transient of about $9 \mathrm{~V}$ and a very small phase shift at the point of trigger is seen and the data goes below $0 \mathrm{~V}$ for $3 \mu \mathrm{s}$ as shown in Fig. 6 . The data also goes beyond the maximum reference level at the instance of trigger which is seen by the shift in the ZCD output.

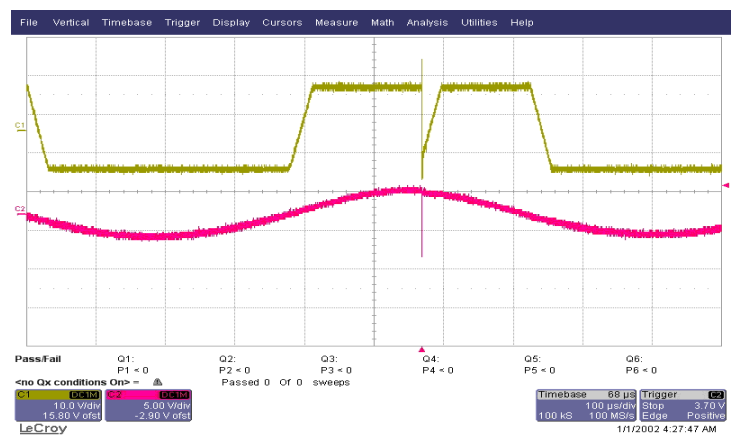

Fig. 6 Effect of ESD at $8 \mathrm{kV}$ and at a distance of $0.7 \mathrm{~m}$

When discharged at a distance of $0.5 \mathrm{~m}$ as shown in Fig. 7, there is a data shift for $5 \mu$ s in the ZCD output showing the transient going below $0 \mathrm{~V}$ at that moment, followed by a small phase shift at the point of trigger.

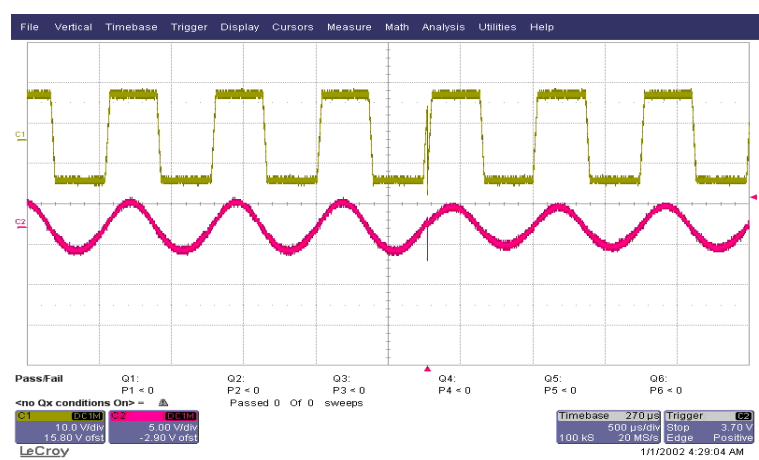

Fig. 7 Effect of ESD at $8 \mathrm{kV}$ and at a distance of $0.5 \mathrm{~m}$ 
Effect of Electrostatic Discharge on Digital and Analog Circuits

The results tabulated are for different distances at a constant voltage of $8 \mathrm{kV}$ from the circuit.

\begin{tabular}{|c|c|c|}
\hline 8kV discharge at $\mathbf{0 . 9} \mathbf{~ m}$ & $\mathbf{8 k V}$ discharge at $\mathbf{0 . 7} \mathbf{~ m}$ & $\mathbf{8 k V}$ discharge at $\mathbf{0 . 5} \mathbf{~ m}$ \\
\hline $\begin{array}{c}\text { Oscillator output went } \\
\text { below } 0 \mathrm{~V} \text { twice and shift } \\
\text { in ZCD output for } 2 \mu \mathrm{s} \text { and } \\
1 \mu \mathrm{s}\end{array}$ & $\begin{array}{c}\text { a very small phase shift at } \\
\text { the point of trigger and } \\
\text { shift in ZCD output for } 3 \mu \mathrm{s}\end{array}$ & $\begin{array}{c}\text { a very small phase shift } \\
\text { shift in ZCD output for } \\
5 \mu \mathrm{s}\end{array}$ \\
\hline
\end{tabular}

Discharge at the ZCD output

\section{DIRECT AIR DISCHARGE}

The following results are observed when air discharge is conducted near the ZCD output of the circuit. There is a transient greater than the reference voltage at the oscillator output for $20 \mu \mathrm{s}$ which is indicated by the shift at the ZCD output. A phase shift and an increase in the amplitude of the next peak by $1 \mathrm{~V}$ are observed in the oscillator output when discharged at $2 \mathrm{kV}$. This is shown in Fig. 8.

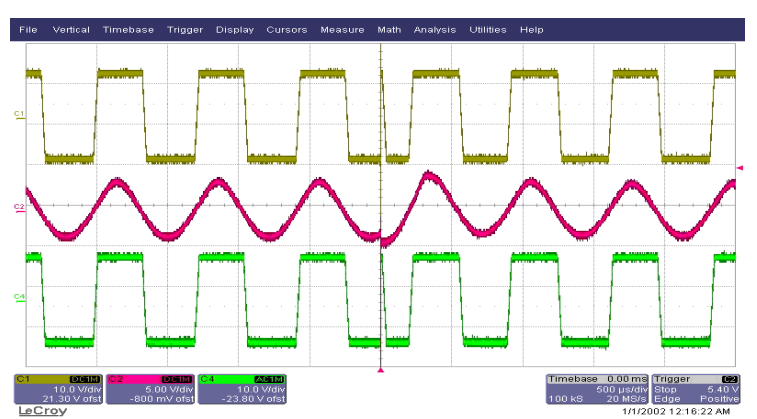

Fig. 8 Effect of ESD at ZCD output for $2 \mathrm{kV}$

When discharged at $4 \mathrm{kV}$ the oscillator output has a large transient and a 180 degree phase shift indicated by the ZCD output shift. Also a decrease in the negative peak amplitude and an increase in the peak amplitude of the next cycle are observed as shown in Fig. 9.

After a discharge of $15 \mathrm{kV}$ at the ZCD output, the digital circuit initially works fine indicating the transition of the oscillator output below the reference voltage. But eventually only the oscillator output recovers and remains intact but both the square wave output and the ZCD output goes to negative saturation around -10V and the IC $\mu \mathrm{A} 741$ is spoilt. This is depicted in the Fig. 10.

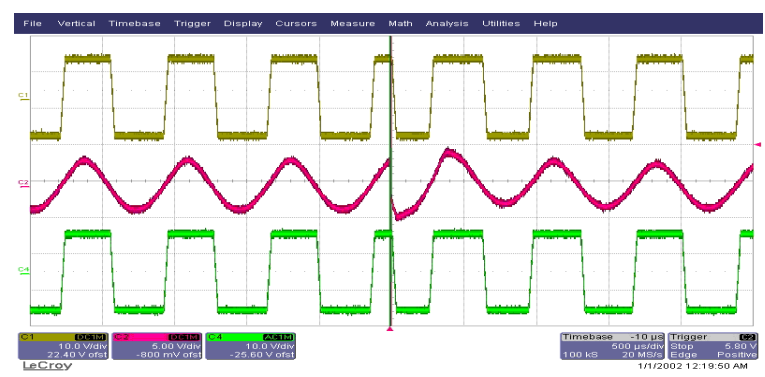

Fig. 9 Effect of ESD at ZCD output for $4 \mathrm{kV}$

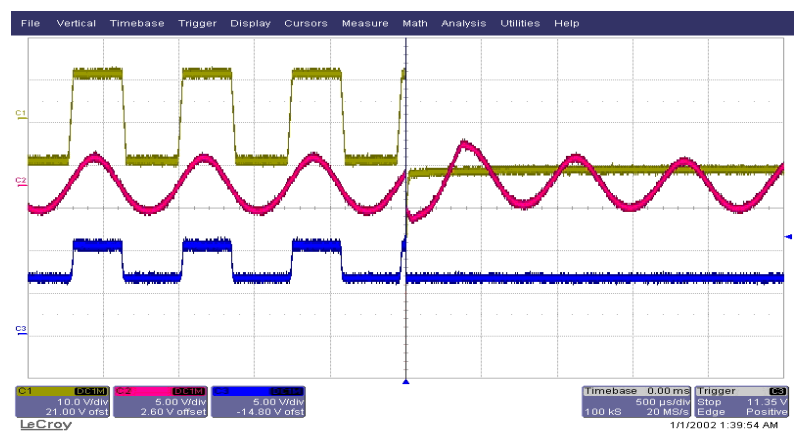

Fig. 10 Effect of ESD at ZCD output for $15 \mathrm{kV}$ 
Effect of Electrostatic Discharge on Digital and Analog Circuits

The results are tabulated for air discharge at ZCD output.

\begin{tabular}{|l|l|l|}
\hline \multicolumn{1}{|c|}{$2 \mathrm{kV}$ discharge } & \multicolumn{1}{|c|}{$4 \mathrm{kV}$ discharge } & \multicolumn{1}{c|}{$15 \mathrm{kV}$ discharge } \\
\hline $\begin{array}{l}\text { ZCD output shift for } 20 \mu \mathrm{s}, \\
\text { oscillator suffers a phase } \\
\text { shift and increase in } \\
\text { amplitude there after }\end{array}$ & $\begin{array}{l}\text { Shift in ZCD output and } \\
180^{\circ} \text { phase shift and } \\
\text { amplitude change for } \\
\text { oscillator output }\end{array}$ & $\begin{array}{l}\text { Phase shift in oscillator } \\
\text { output and then recovers, } \\
\text { ZCD output goes to } \\
\text { negative saturation }\end{array}$ \\
\hline
\end{tabular}

\section{Discharge at the Oscillator output}

When a $2 \mathrm{kV}$ air discharge is given to the pickup point at oscillator output the sine wave had a large transient which is indicated by the shift in the ZCD and there is an increase in the amplitude by $2 \mathrm{~V}$ in the next peak of the sine wave. This is shown in Fig. 11.

A discharge of $4 \mathrm{kV}$ at the oscillator output results in a transient greater than $60 \mathrm{~V}$ at the oscillator output followed by an increase in the negative peak voltage greater than $0 \mathrm{~V}$, also observed is the shift in the $\mathrm{ZCD}$ output for $60 \mu \mathrm{s}$ and an increase in the peak voltage of the next peak by $2 \mathrm{~V}$. This is shown in Fig. 12.

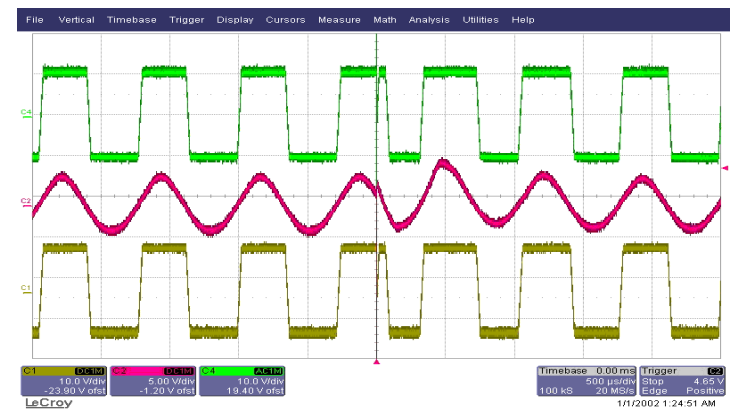

Fig. 11 Effect of ESD at oscillator output for $2 \mathrm{kV}$

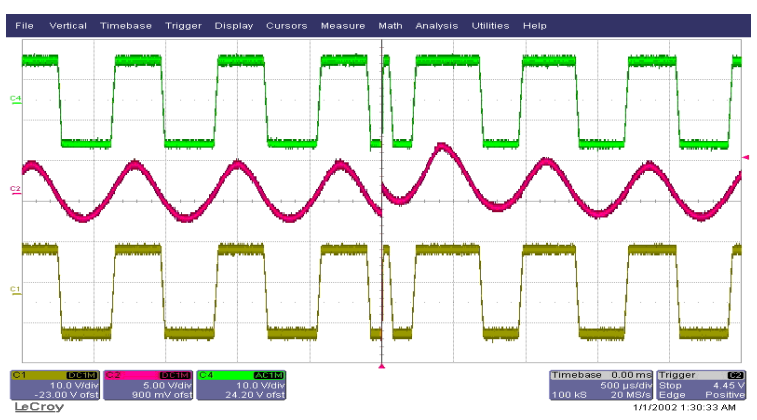

Fig. 12 Effect of ESD at oscillator output for $4 \mathrm{kV}$.

A discharge of $8 \mathrm{kV}$ at the oscillator output results in a transient which goes below the reference voltage for $40 \mu \mathrm{s}$ and then the oscillator output remains above the reference voltage for $750 \mu \mathrm{s}$. Also the ZCD output remains high for entire period of $750 \mu \mathrm{s}$ as shown in Fig. 13.

When discharged for $15 \mathrm{kV}$ the oscillator output goes below $0 \mathrm{~V}$ for $40 \mu \mathrm{s}$. A large transient at the ZCD after $40 \mu \mathrm{s}$ shows that the oscillator output goes below and beyond the reference after which the oscillator output remains above $0 \mathrm{~V}$ for $1.7 \mathrm{~ms}$ after which it regains its original functionality. Meanwhile the ZCD output remains at high till analog output recovers. This is shown in Fig. 14. The analog circuit output recovered earlier compared to the digital output.

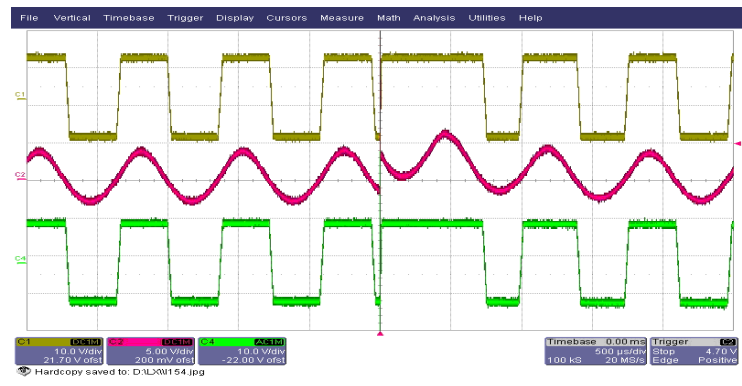

Fig. 13 Effect of ESD at oscillator output for $8 \mathrm{kV}$. 


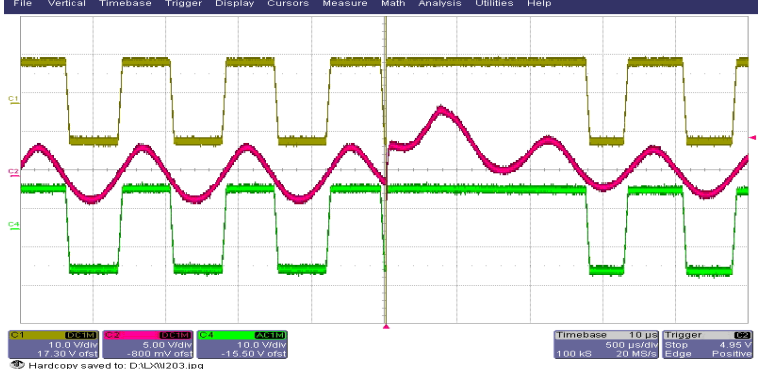

Fig. 14 Effect of ESD at oscillator output for $15 \mathrm{kV}$

The results are tabulated for air discharge at oscillator output.

\begin{tabular}{|c|c|c|c|}
\hline $\begin{array}{c}2 \mathrm{kV} \text { discharge at } \\
0.9 \mathrm{~m}\end{array}$ & $\begin{array}{c}4 \mathrm{kV} \text { discharge at } \\
0.9 \mathrm{~m}\end{array}$ & $\begin{array}{c}8 \mathrm{kv} \text { discharge at } \\
0.9 \mathrm{~m}\end{array}$ & $\begin{array}{c}15 \mathrm{kV} \text { discharge at } \\
0.9 \mathrm{~m}\end{array}$ \\
\hline $\begin{array}{l}2 \mathrm{~V} \text { increase in } \\
\text { amplitude and shift } \\
\text { in ZCD output }\end{array}$ & $\begin{array}{l}\text { Oscillator output } \\
\text { has } 60 \mathrm{~V} \text { transient, } \\
2 \mathrm{~V} \text { increase in } \\
\text { amplitude and ZCD } \\
\text { output change for } \\
60 \mathrm{us}\end{array}$ & $\begin{array}{l}\text { Oscillator } \\
\text { goes below reference } \\
\text { for } 40 \mu \mathrm{s} \text {, oscillator } \\
\text { and ZCD output } \\
\text { remain high for } \\
750 \mathrm{us}\end{array}$ & $\begin{array}{l}\text { Oscillator } \\
\text { below 0V for } 40 \mu \mathrm{s} \\
\text { and ZCD has huge } \\
\text { transient and remains } \\
\text { high till analog } \\
\text { recovers }\end{array}$ \\
\hline
\end{tabular}

V.

CONCLUSIONS

The effect of ESD on the digital data is more pronounced when compared to the analog data. From the above experimental results it can be definitely said that the digital data is more susceptible to ESD due to its smaller size and larger complexity when compared to the analog circuits. It can be seen that the analog circuit can come back to its initial working condition (even sometimes after certain latency period due to the slow discharge of charges accumulation) even after the ESD affecting it, but a digital circuit gets damaged quickly to electrostatic discharge.

In the indirect discharge it is seen that the ESD effect depends on both the distance and the discharge voltage. Higher discharge voltage and shorter distance produces larger data losses and larger transients. The digital circuit gets damaged at higher discharge voltage. The analog circuit with discreet components is affected by ESD but it recovers back quickly.

\section{REFERENCES}

[1] James E. Vinson And Juin J. Liou, “Electrostatic Discharge In Semiconductor Devices: An Overview', Proceedings of the IEEE, Vol. 86, No. 2, February 1998, Pp 399-418.

[2] B. Greason, "Dynamics of the basic ESD event," 1993, EOS/ESD Tutorial Notes, pp. E-1-E-21, Sept. 1993.

[3] C. Diaz, S. M. Kang, and C. Duvvury, "Tutorial electrical overstress and electrostatic discharge,” IEEE Trans. Reliability, vol. 44, pp. 2-5, Mar. 1995.

[4] W. D. Greason and G. S. P. Castle, "The effects of ESD on microelectronic devices-A review," IEEE Trans. Industrial Applications, vol. IA-20, pp. 247-252, Mar./Apr. 1984.

[5] C. Duvvury and A. Amerasekera, "ESD: A pervasive reliability concern for IC technologies," Proc. IEEE, vol. 81, pp. 690-702, May 1993.

[6] Hongxia Wanga, Samuel V. Rodrigueza, Cagdas Dirika \& Bruce Jacoba, "Electromagnetic Interference and Digital Circuits: An Initial Study of Clock Networks", Electromagnetics, Volume 26, Issue 1, 2006, pp 73-86.

[7] Ming-Douker, Jeng-Jie Peng and Hsin-Chin Jiang, "Failure Analysis of ESD damage in a high-voltage driver IC and the effective ESD protection solution", Proceedings of 9th IPFA 2002, Singapore, pp 84-89.

[8] C. Duvvury, R.N.Rountree and O. Adams, “Internal chip ESD phenomena beyond the protection circuit”, IEEE Transactions on Electron Devices, Vol. 35, No. 12, 1988, pp 2133-2139.

[9] Robert Ashton, ON Semiconductor "Reliability of IEC 61000-4-2 testing on components", EE Times Design article, 8/10/2008.

[10] Robert Ashton, "System level ESD Testing-The Test setup", Challenges in testing, Conformity, December 2007, pp 34-40. 